\title{
Correlation studies of Mg concentration in Joint fluid of Arthritis patients under the treatment of Indigenous and Modern medicinal system
}

\author{
Research Article
}

\author{
Avni Karvat $^{1}$, Hemlata Bagla $^{1}{ }^{*}$, Vikram Londhey $^{2}$, Sriram Savrikar $^{3}$, Mukund Sabnis $^{4}$ \\ 1. Department of Nuclear and Radiochemistry, Kishinchand Chellaram College, \\ Churchgate- 400020, India.
}

2. B.Y.L Nair Charitable Hospital \& TN Medical College, Dr. A.L. Nair road, Mumbai400008, India. Email ID:- vikramlondhey@yahoo.com

3. R A Podar Ayurvedic College and Hospital, Worli, Mumbai 400018, India.

4. Email ID:-sssavrikar@gmail.com

5. Jeevanrekha Ayurved Chikitsalaya \& Research Center, Seawoods, Nerul West, Navi

Mumbai - 400 706, India. Email ID:- jeevanrekha1996@rediffmail.com

\begin{abstract}
Magnesium ( $\mathrm{Mg})$, an essential cation is abundantly found in skeletal and cardiac muscle cells. It is necessary to investigate the role of essential elements in joint effusion as they may serve as non-invasive diagnostic tool for the characterization of joint diseases. In the present paper, the concentration of $\mathrm{Mg}$ localized in joint fluid of arthritis patients under the treatment of Allopathy and Polyherbal formulations has been carried out. The quantitative assessment of $\mathrm{Mg}$ was determined by Inductively Coupled Plasma Atomic emission spectroscopy (ICP-AES). The patients with cases of proved Osteoarthritis (OA), Rheumatoid arthritis (RA) and Bursitis were included for the study. Synovial (SF) and Bursal fluid (BF) samples were aspirated by arthrocentesis. The levels of $\mathrm{Mg}$ were found to be significantly lesser $(\mathrm{P}<0.05)$ in arthritis patients under the treatment of modern medicines when compared to controls. However patients under the treatment of PF showed levels of $\mathrm{Mg}$ highly comparable to controls. Subsequently the possible prevalence of dwindling $\mathrm{Mg}$ in joint effusions has been inferred as a potential diagnostic biomarker in etiology of arthritis. Furthermore the therapeutic impact of $\mathrm{PF}$ due to bioavailable form of $\mathrm{Mg}$ implicates a stimulus for adept joint health.
\end{abstract}

Keywords: Synovial fluid, Osteoarthritis, Rheumatoid Arthritis, Bursitis, Magnesium, Polyherbal formulation.

\section{Introduction}

Over the last few years there is an extensive advancement in analysis of trace

*Corresponding Author:
Hemlata Bagla,
Department of Nuclear and
Radiochemistry,
Kishinchand Chellaram College,
Churchgate - 400020
E,mail - hemabagla@ gmail.com
Mob: +91-9821420698

elements by the development of ICP-AES especially for liquid samples. ICP-AES provides excellent analytical features, such as high sensitivity for elements, wide linear dynamic ranges of calibration curves and simultaneous multielement detection capabilities. These analytical features clearly implicate its detection usability over a wide range, i.e., ppm to ppb level in different geochemical, biological and environmental samples. 
Previously, trace metals were typically analyzed using colorimetric techniques, which were both cumbersome and subject to interferences, or flame atomic absorption techniques, which although almost interference free, were labor intensive owing to their one element at a time analytical mode. Also analytical techniques like Neutron Activation Analysis usually require a nuclear reactor and a long irradiation time for some elements to be determined. Furthermore the furnace atomic absorption technique, the standard bearer of low-level trace metal analysis for years, is giving way to axial viewed ICP-AES.

This advanced technique has upshot a new arena in biochemical research on trace elements, it has been elucidated that various biological and physiological functions of organs substantially depend on the kinds and concentration levels of the elements contained in cells and organs. As a result bio-essential elements such as $\mathrm{Mg}, \mathrm{Cu}$, and $\mathrm{Zn}$ are known to play crucial role in different biological and physiological functions.

As $\mathrm{Mg}$ plays a major role in bone formation and metabolism it becomes essential to study its role in etiology of arthritis. Among the different joint diseases, Osteoarthritis (OA), Rheumatoid Arthritis (RA) and Bursitis accounts for most diagnosed musculoskeletal disorder. The 'synovium' is the primary site of pathology in Arthritis. The 'synovial fluid' (SF) is an ultrafiltrate of blood plasma present in between the synovial joints. Also inbetween the joints the synovial fluid is filled in the sacks called 'bursae'. The bursae's job is to assist in the muscle/joints movement by cushioning the joints and bones against friction. During inflammation or injury bursitis arises due to accumulation of inflamed fluid known as Bursal fluid (BF). The chemical components of cartilage and joint fluid degradation provide information about their anabolism or catabolism. Therefore, analysis of joint fluid becomes crucial in assessment of these diseases since, the composition of the fluid can reflect either a transudative or exudative etiology. Moreover $\mathrm{Mg}$ is known to be a factor in maintaining the lubricating property of SF.

Several in vivo studies suggest a positive correlation between $\mathrm{Mg}$ deficiency and reduced bone density $(1,2)$. Few cases of hypomagnesemia in animal models were reported with osteopenia, chondrocalcinosis, osteoporosis and reduced bone density. Further studies on animal model have proved that hypomagnesemia leads to diminution in skeletal Mg content (3).

$\mathrm{Mg}$ depletion has also been strongly indicated as a risk factor for osteoporosis associated with aging and postmenopausal status. The studies on $\mathrm{Mg}$ supplementation in osteoporotic women resulted in slower bone loss and fewer fractures in supplemented women than in unsupplemented women (4-6).

A study demonstrated the widespread extent of magnesium whitlockite deposition in human articular cartilage concluded its possible roles in opportunistic mode of formation of articular tissues (7).

The magnesium ion plays a significant role as an intracellular catalyst in bone turnover, being vitally involved in the enzyme activities of phosphorylases and phosphatases. Researchers have reported low values of magnesium and alkaline phosphatase activity in the synovial fluid of pseudogout patients. (8, 9).

Though, much information about $\mathrm{Mg}$ potency and its relation with skeletal muscles and bone health have been reported in the literature. Very little is known about its therapeutic role in polyherbal formulation (PF). It is known that essential elements are in bioavialable form in herbs and are thus easily metabolized by the body. 
Therefore, the present work focuses on the comparative study of the effect of variation in the concentration of $\mathrm{Mg}$ in joint fluid of patients under the treatment of Allopathy and Polyherbal Formulations. Also it evaluates the prevalence of $\mathrm{Mg}$ and its possible impact in arthritic joint fluid. Subsequently, ICPAES was used as the method of choice as it was anticipated that the greater precision of this method of analysis would add avenues in its applicability in biomedical research.

\section{MATERIALS AND METHODS Reagents and Standard solutions}

Analytical grade Reagent was obtained from Lennetech Laboratory whereas Suprapur grade (Merck) of Nitric acid $\left(\mathrm{HNO}_{3}\right)$ and Perchloric acid $\left(\mathrm{HClO}_{4}\right)$ acids were employed for sample digestion. Standards for calibration were diluted from $1000 \mathrm{ug} / \mathrm{mL}$ stock solutions. The multielemental standard of ultrapure quality was acquired from Merck (Germany).

\section{Study population}

The samples of SF/BF were aspirated from diagnosed patients of knee Bursitis, RA and OA by arthrocentesis. The arthritis patients who attended the outpatient department of B.Y.L Nair, Navneet and Jeevan Rekha hospital were evaluated as per the criteria laid by American College of Rheumatology (ACRC). Healthy adult individuals were considered as controls. The permission of ethic committee of respective hospital was obtained and the Declaration of Helsinki (1964) was followed during the research procedure (10). Patients included were male and female of age group ranging from 18 to 90 years. Exclusive criteria of patients comprised of pregnant females, HIV patients and subjects suffering from chronic disease such as cancer. The patient population was categorized into two sets;
Cateogory A: - Patients intaking allopathy medicines [n=135].

The samples of SF/BF were obtained from patients under the treatment of most widely used allopathic medicine Celecoxib (Non-Steriodal Antiinflammatory Drug, NSAID) at the dosage of $400 \mathrm{mg} /$ day. The samples of joint fluid were represented as AL-OA, AL-RA and AL-B. The patient's population included 44 patients of AL-OA, 50 of AL-RA and 41 AL-B.

\section{Category B:-Patients under the treatment of Polyherbal Formulation (PF) [n=142].}

The OA patients under the treatment of oral administration of formulated poly herb Relistif were designated as PF-OA. The patients were given 2 capsules a day which constituted $0.300 \mathrm{~g}$ of Relistif drug. The herbal constituent of the formulation are Celery seeds, Curcuma Longa, Cyperus Rotundus and Piper Longum.

The oral dosage of $0.350 \mathrm{~g}$ present in each Rumaquit tablet (supplied by Jeevanrekha ayurved chikitsalaya \& Research Center) was administered to PFRA patients and it was composed of Tinospora Cordifolia, Withania Somnifera, Tribulus Terrestris and Zingiber officinale

The Bursitis patients were administered 2 tablets $(0.540 \mathrm{~g})$ of Triphala labeled as PF-B. It was composed of Terminalia Chebula, Terminalia Belerica and Phyllantus Emblica. In addition to that patients under the treatment of $\mathrm{PF}$ considered for $\mathrm{SF} / \mathrm{BF}$ tapping were 42 PF-OA, 58 PF-RA and 42 PF-B patients.

Each patient was treated with the respective medication for the duration of 3 months. The control comprised of 46 healthy adult volunteers. Every patient and control was imparted with complete information and written consent. 
The patients population were further subdivided into three sets on the basis of gender and age ie.

Group I: Males with age less than 40 years.

Group II: Males with age more than 40 years.

Group III: Females with age less than 40 years.

Group IV: Females with age more than 40 years.

\section{Sample aspiration}

Arthrocentesis was used to obtain SF by inserting needle into the joint space. Strict aseptic techniques were used when $\mathrm{SF} / \mathrm{BF}$ was aspirated from knee joints of patients. SF Samples were stored in autoclave sterile vials. These containers were pre-cleaned by keeping them in contact with $5 \% \mathrm{HNO}_{3}$ overnight and then they were rinsed with high purity water. Samples were frozen at $-5^{\circ} \mathrm{C}$ until assayed and were later centrifuged to precipitate cells and particles. A $2 \mathrm{~mL}$ aliquot of the clear fluid was transferred to an Eppendorf capsule and stored in sterile vials kept at $5^{\circ} \mathrm{C}$ until further analysis.

\section{Instrumentation}

The spectral changes determined by spectroscopic methods, represented the fluid biochemistry. The present work was performed using ARCOS ICP-AES device ( $\mathrm{M} / \mathrm{s}$. Spectro, Germany) in Indian Institute of Technology, Sophisticated Analytical Instrument Facility (SAIF), Mumbai. Sample digestion was done by 1:1 conc $\mathrm{HNO}_{3}$ and conc $\mathrm{HClO}_{4}$. All the samples were finally screened for $\mathrm{Mg}$ content in triplicate series. The sample solution was analyzed against calibration curve. The presence of $\mathrm{Mg}$ is identified by wavelength of emitted radiation $(\mathrm{Mg}=279.55 \mathrm{~nm}, \quad 279.07 \mathrm{~nm}, \quad 280.27 \mathrm{~nm}$, $285.21 \mathrm{~nm}$ ) and the concentration was calculated by intensity of radiation. The
Instrumental characteristics and operating parameters are given in Table 1.a

\section{Statistical analysis}

All statistical analyses were conducted with the use of Graphpad prism software(version 5). Data were expressed as Mean \pm SD. The difference of parameters between patients and controls were tested by ANOVA. The evaluation of pre and post effect of patients groups under the treatment of Allopathy and PF therapy were tested by using matched pair Wilcoxon's T test. Spearman correlation test was conducted to evaluate the possible association of elemental concentration of various groups with the age of patients. Statistical significance was set at the 5\% level.

$\begin{array}{lrr}\text { Table1.a: } & \text { ICP-AES } & \text { instrument } \\ \text { characteristics } & \text { and } & \text { operating }\end{array}$
parameters.

\begin{tabular}{|l|l|}
\hline PARAMETERS & SETTING \\
\hline RF Generator & $1000 \mathrm{watts}$ \\
\hline Power required & $220 \pm 10 \mathrm{~V}$ \\
\hline Flame Temperature & $11000 \mathrm{~K}$ \\
\hline Plasma & Argon \\
\hline Spectra Range & $189-800 \mathrm{~nm}$ \\
\hline Coolant Flow & $12 \mathrm{~L} / \mathrm{min}$ \\
\hline Auxillary Flow & $1 \mathrm{~L} / \mathrm{min}$ \\
\hline Nebulizer & $0.8 \mathrm{~L} / \mathrm{min}$ \\
\hline Sensitivity & $\begin{array}{l}\text { ppb level of } \\
\text { detection }\end{array}$ \\
\hline
\end{tabular}

\section{RESULTS}

The student $\mathrm{T}$ test performed for all the groups of patients under the treatment of Allopathy drug (Table 1.b) showed significantly $(\mathrm{P}<0.05)$ lower mean $\mathrm{Mg}$ concentration in AL-OA and AL-RA when compared to controls before the treatment. Whereas the amount of $\mathrm{Mg}$ was significantly $(\mathrm{P}<0.05)$ increased in $\mathrm{AL}-\mathrm{B}$ patients before the treatment. 
Table 1.b: The variation of $\mathrm{Mg}(\mathrm{Mean} \pm \mathrm{SD})$ concentration in the Joint fluid of Controls and patients under the Pre and Post-Treatment of Allopathic drugs.

\begin{tabular}{|l|l|l|l|l|l|l|l|}
\hline \multirow{3}{*}{ Groups } & \multicolumn{9}{|l|}{ Mg concentration in Joint fluid of patients under } & \multirow{3}{*}{ Allopathy Treatment* } & \multirow{2}{*}{ Controls } \\
\cline { 2 - 8 } & OA & RA & \multicolumn{2}{|l|}{ Bursitis } & \\
\cline { 2 - 7 } & Pre & Post & Pre & Post & Pre & Post & \\
\hline I & $18.3 \pm 0.2$ & $21.5 \pm 0.4$ & $12.5 \pm 0.4$ & $13.5 \pm 0.4$ & $33.5 \pm 0.2$ & $35.5 \pm 0.4$ & $29.5 \pm 0.26$ \\
\hline II & $15.4 \pm 0.2$ & $17.8 \pm 0.5$ & $8.6 \pm 0.3$ & $9.8 \pm 0.4$ & $31.8 \pm 1.0$ & $32.0 \pm 0.3$ & $25.3 \pm 0.37$ \\
\hline III & $18.4 \pm 0.3$ & $19.4 \pm 0.3$ & $10.4 \pm 0.2$ & $11.7 \pm 0.3$ & $35.5 \pm 0.3$ & $37.4 \pm 0.2$ & $27.4 \pm 0.30$ \\
\hline IV & $15.0 \pm 0.4$ & $15.9 \pm 0.3$ & $6.9 \pm 0.4$ & $7.7 \pm 0.5$ & $28.4 \pm 0.2$ & $29.1 \pm 0.2$ & $23.5 \pm 0.45$ \\
\hline
\end{tabular}

*Mean $\pm S D(m g / L)$

The Graph 1.a clearly indicates a distinct concentration of $\mathrm{Mg}$ in the three types of arthritis under study. Therefore diminished $\mathrm{Mg}$ levels in the current data are very much evident in arthritic condition like AL-OA and AL-RA. Our data on Mg levels in SF (Graph 1.a) of AL-RA and AL-OA patients are supported on the basis of research presented by Tuncer etal (11). In case of bursitis, it is the first ever attempt made in the path of detection of trace elements in bursal effusion. Hence further investigation is required to give the strong scientific evidences.

It was further observed (Graph 1.b) that the mean $\mathrm{Mg}$ levels after the 12 weeks treatment of Allopathic drugs showed significant $(\mathrm{P}<0.05)$ increase in $\mathrm{Mg}$ levels though, the levels were not very much comparable to controls. The levels of $\mathrm{Mg}$ showed further augmentation in case of AL-B patients. A negative correlation in AL-OA $(r=-0.7206$,
$\mathrm{P}<0.05)$, RA patients $(\mathrm{r}=-0.8292, \mathrm{P}<0.05)$ and Bursitis $(\mathrm{r}=-0.5221 \mathrm{P}<0.05)$ was observed between levels of $\mathrm{Mg}$ and age indicating $\mathrm{Mg}$ deficiency is more prevalent in aged patients.

The patients under the medication therapy of PF were PF-OA being treated by Relistif, PF-RA consuming Rumaquit and PF-B Bursitis patients intaking Triphala powder demonstrated remarkable fluctuations in the level of $\mathrm{Mg}$ (Table 1.c)

The mean concentration of $\mathrm{Mg}$ after 12 weeks treatment with polyherbal Formulation showed significant improvement in post treatment groups (Graph 1.d) when compared to pre treatment groups (Graph 1.c). On the other hand, there was significant difference $(\mathrm{P}<0.05)$ between $\mathrm{PF}$ groups and controls. Such variation observed in case of PF-RA and PF-OA may be due to higher activity of disease which may require more time span to display an accurate therapeutic effect.

Table 1.c: The variation of $\mathrm{Mg}(\mathrm{Mean} \pm \mathrm{SD})$ concentration in the Joint fluid of Controls and patients under the Pre and Post-Treatment of Polyherbal Formulations.

\begin{tabular}{|c|c|c|c|c|c|c|c|}
\hline \multirow{3}{*}{ Groups } & \multicolumn{6}{|c|}{$\begin{array}{c}\text { Mg concentration in Joint fluid of patients under Polyherbal } \\
\text { Formulation treatment* }\end{array}$} & \multirow{2}{*}{ Controls } \\
\cline { 2 - 7 } & \multicolumn{2}{|c|}{ OA } & \multicolumn{2}{c|}{ RA } & Bursitis & \\
\cline { 2 - 7 } & Pre & Post & Pre & Post & Pre & Post & \\
\hline I & $19.4 \pm 0.2$ & $25.3 \pm 0.3$ & $12.4 \pm 0.2$ & $20.7 \pm 0.7$ & $35.5 \pm 0.2$ & $31.5 \pm 0.2$ & $29.5 \pm 0.26$ \\
\hline II & $17.2 \pm 0.2$ & $21.5 \pm 0.6$ & $10.5 \pm 0.3$ & $16.6 \pm 0.2$ & $32.5 \pm 0.2$ & $28.2 \pm 0.5$ & $25.3 \pm 0.37$ \\
\hline III & $18.8 \pm 0.5$ & $22.3 \pm 0.3$ & $11.4 \pm 0.2$ & $18.5 \pm 0.3$ & $37.4 \pm 0.3$ & $32.3 \pm 0.4$ & $27.4 \pm 0.30$ \\
\hline IV & $16.4 \pm 0.3$ & $19.5 \pm 0.2$ & $9.47 \pm 0.2$ & $15.6 \pm 0.5$ & $31.4 \pm 0.2$ & $30.4 \pm 0.2$ & $23.5 \pm 0.45$ \\
\hline
\end{tabular}


Graph 1.a: Variation in the levels of Mg in joint fluid of Controls and (AL-OA, AL-RA \& AL-B) patients under the Pre Treatment of Allopathic drugs.

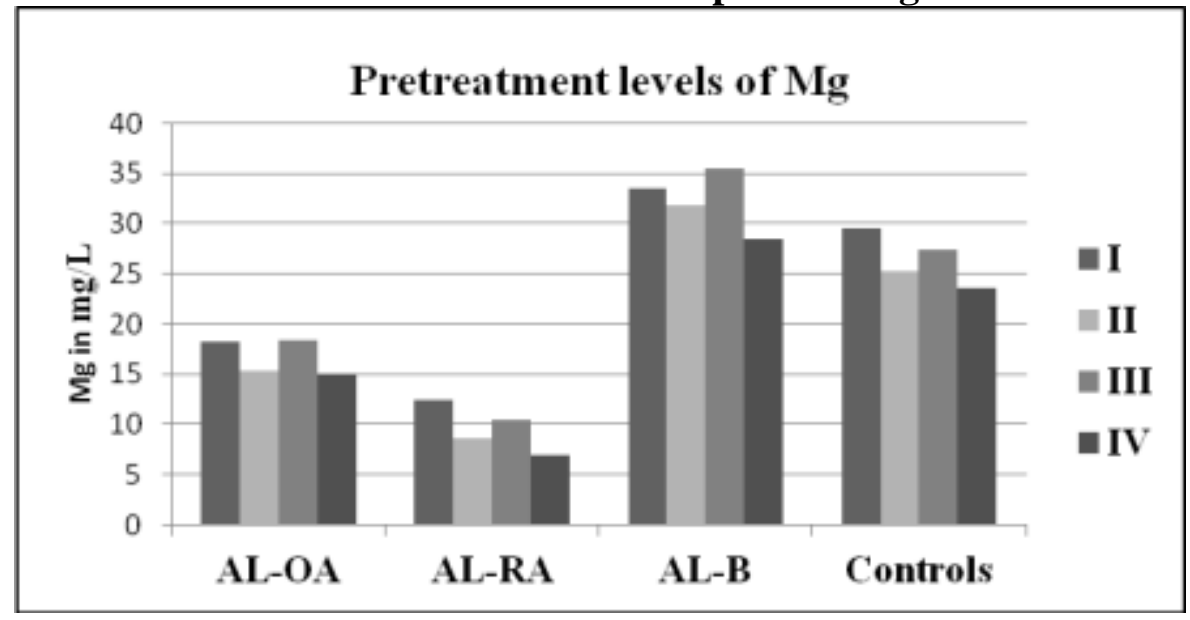

Graph 1.b: Variation in the levels of Mg in joint fluid of Controls and (AL-OA, AL-RA \& Al-B) patients under the Post Treatment of Allopathic drugs.

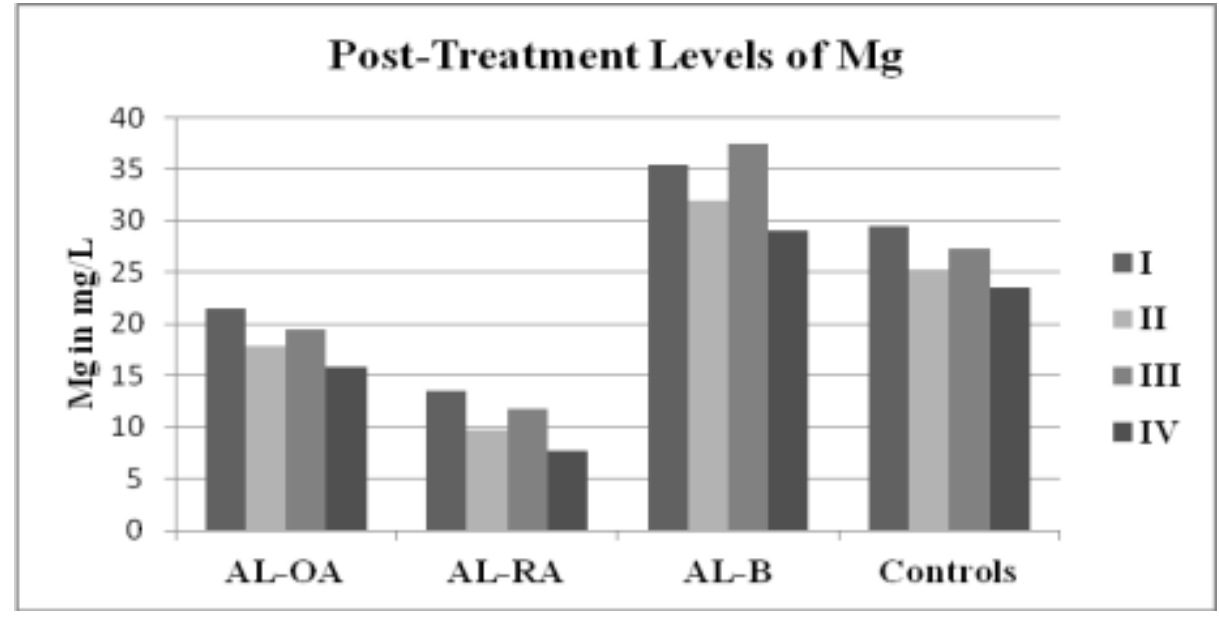

Graph 1.c: Variation in the levels of $\mathrm{Mg}$ in joint fluid of Controls and (PF-OA, PF-RA \& PF-B) patients under the Pre Treatment of Polyherbal Formulations.

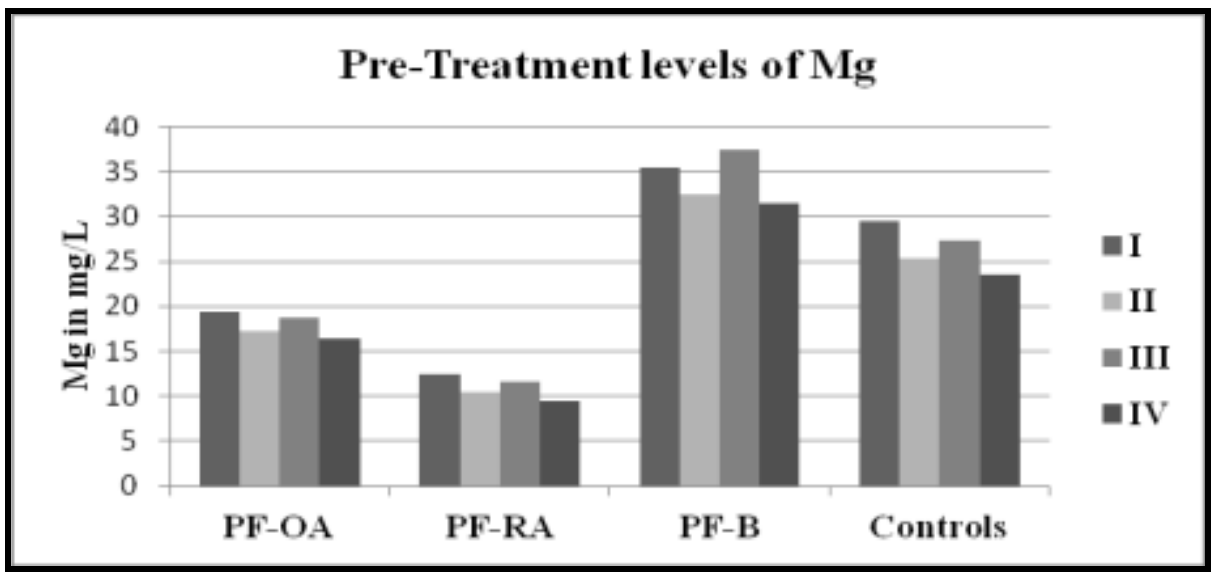


In addition to that when the levels of $\mathrm{Mg}$ was compared for both the categories of patients i.e. patients under allopathy and Polyherbal Formulations, it was found that the levels of $\mathrm{Mg}$ were quite distinct. Furthermore, augmented amount of $\mathrm{Mg}$ was found in patients under the treatment of Polyherbal Formulations.

\section{Graph 1.d: Variation in the levels of $\mathrm{Mg}$ in joint fluid of Controls and (PF-OA, PF-RA \& PF-B) patients under the Post Treatment of Polyherbal Formulations.}

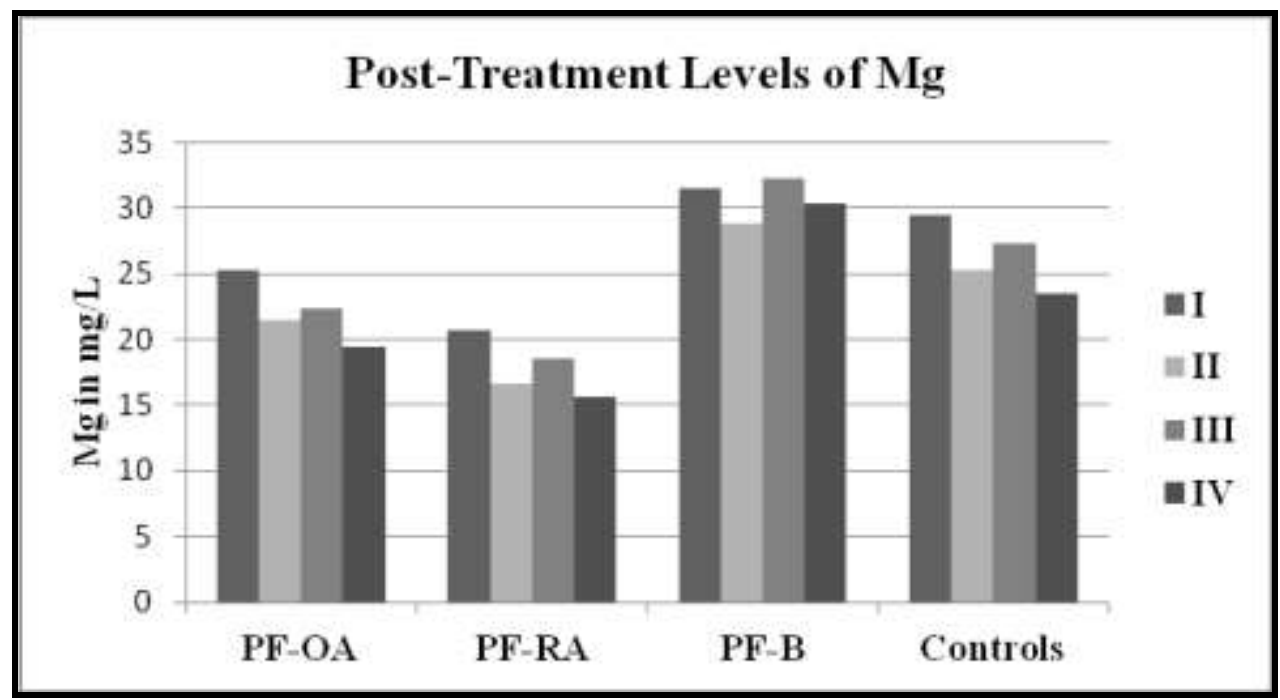

\section{Discussion}

$\mathrm{Mg}$ plays a significant role in bone and joint as it can be seen from the diminished levels of $\mathrm{Mg}$ in $\mathrm{SF}$ of $\mathrm{OA}$ and RA knee joint. It was further observed that the female patients had reduced concentration of $\mathrm{Mg}$ than the male counterpart. Moreover, the $\mathrm{Mg}$ levels showed inverse relationship with the age of both male and female patients.

The presences of $\mathrm{Mg}$ catalyses the synthesis of certain substance in SF which inhibit the production of enzyme hyaluronidase(12) which has the ability to degrade SF and consequently contributes to enervated joint health. It was suggested that the explanation may lie in the importance of $\mathrm{Mg}$ to metabolism, or the increased free radical production and proinflammatory effects of low $\mathrm{Mg}$ (13). The prevalence of lower level of $\mathrm{Mg}$ concentration in transcellular fluid (SF) encompassed in diseased knee joint could be explained by decreased $\mathrm{Mg}$ resorption in bone as well as increased calcification in soft tissue. Mg-deficiency is known to cause disturbance in skeletal growth as well as brittle and hypermineralized bone. Thus at both the physical and chemical level there is no discrete boundary between cartilage and synovial fluid, there being a small but important area of the joint in which components of both are mixed. However, such a change in mineral concentration in the human tissues and fluids plays an important role in health and disease conditions as they are the important components of the antioxidant enzyme defence system (14).

Our work on investigation of $\mathrm{Mg}$ in SF of OA and RA patients showed lower levels of $\mathrm{Mg}$, exemplifying it as one of the contributory factor in disease state. Researchers have suggested that $\mathrm{OA}$ is associated with thickening of the subchondral bone with an abnormally low mineralization pattern (15), such that lower levels of $\mathrm{Mg}$ may predispose to the development of OA. Although previous 
reports on plasma and erythrocyte $\mathrm{Mg}$ levels of the RA patients showed slight or insignificant reductions when compared to controls. Levels of $\mathrm{Mg}$ were also associated with erythrocyte SOD activity $(11,16)$. Also $\mathrm{Mg}$ deficiency led to increased in a skeleton substance $\mathrm{P}$, a neuropeptide which resulted in excess stimulation of cytokines -IL1beta, TNF alpha (17). These cytokines can stimulate the production of collagenase and prostaglandin by synovial cells and thus are believed to contribute to joint damage in inflammatory conditions such as RA. Also further decrease in amount of $\mathrm{Mg}$ in RA is due to the long span of disease condition leading to worsening of joint mobility.

The post treatment alteration showed slight increase in $\mathrm{Mg}$ concentration of patients intaking NSAID. However better evidences can be given by evaluating the metabolic status of $\mathrm{Mg}$ in SF and its possible changes due to medication. Furthermore, our result describes augmented concentration of $\mathrm{Mg}$ in $\mathrm{BF}$ than control. No evidences have been cited in the literature regarding the possible role of $\mathrm{Mg}$ in $\mathrm{BF}$. The possible explanation may be, in disease condition, metalloenzymatic reactions of the fluid must be influenced and increased, causing the concentrations of the essential nutrients to be altered.

In order to find a better therapeutic without side effect for arthritis. PF therapy was used to compare the effectivity of ayurvedic ailment verses allopathy treatment. It was found that the content of $\mathrm{Mg}$ in $\mathrm{PF}$ was comparatively higher in Rumaquit and Triphala than in Relistif. The higher level of $\mathrm{Mg}$ is indicative of its presence in herbs which were part of the formulations. These herbs are widely known for its inflammatory properties (1820).

The investigation of $\mathrm{Mg}$ in the $\mathrm{SF} / \mathrm{BF}$ after three months treatment therapy led us to conclude that $\mathrm{Mg}$ status of arthritis patients under PF treatment where higher than allopathy patients. Further intriguing evidences proved by questionnaire from patients in case of PFOA showed ease in mobility after the treatment and without any side effects. However, we suggest that SF Mg levels, which are known to vary quite widely in patients with PF-RA, may stabilise probably after longer duration of treatment. Analysis of variance was used to test the hypothesis of significance among the mean values of $\mathrm{Mg}$ in SF. Polyherbs in PF provide a complex system of proteins to ensure that the essential metals are rarely allowed to be "free" to produce any scavenging effect.

Relistif is a polyherbal formulation which contain herbs rich in phenolic compounds. The phenolic compounds and $\mathrm{Mg}$ together have the capacity to quench lipid peroxidation, prevent DNA oxidative damage and scavenge reactive oxygen species such as superoxide hydrogen peroxide and hydroxyl radical $(21,11)$. Hence the formulation proved to be highly effective in treatment of OA patients where degradative alteration due to oxidative stress leads to detoriation in joint health

In addition to that Rumaquit being an herbal formulation is suggested to contain elements in bioavailable form that favourably influence the levels of essential elements and possibly increase the body's ability to skirmish against development of arthritis. Since serotonin, histamine and prostaglandin are major mediators of inflammation. Anti-inflammatory effects are due to polyherbs; Curcuma longa(22), Tinospora cordifolia(23), Withania Somnifera(24), Tribulus terrestris(25) and Ginger officinale (26) as they are known to probably exert an inhibitory effect on some of the mediators of inflammation.

Little information exists on the molecular and biochemical pathophysiology of knee bursitis. Clinical data suggests that elevated levels of 
expression of cytokines (interleukin [IL]$1 \beta$, IL-1, IL-6, tumor necrosis factor [TNF] $\alpha$, small inducible cytokines), metalloproteases, and cyclooxygenases contribute significantly to bursitis (27). The immediate cause of an acute simple bursitis appears to be rupture of one of the large and delicate vessels in its wall whereas in case of septic bursitis the pathogensis is mainly due to microorganism. Triphala powder along with bioavailable $\mathrm{Mg}$ inhibits the activity of hyaluronidase and matrix metalloproteinases (MMPs) activity which degrades cartilage matrix (28-30). Our study on high $\mathrm{Mg}$ concentration may be a predisposing factor for Bursitis.Triphala induces modulated $\mathrm{Mg}$ concentrations in PF-B patients when compared to controls.The relation between $\mathrm{Mg}$ concentrations and Triphala treatment and the efficacy of a preventive or curative therapy, or both, of this effect with $\mathrm{Mg}$ remains to be investigated. Confounders may be the reason for the dissimilar results. Modulating factors other than the reported risk factors may also exist.

The current study, thus elucidates the prospective disposition of Magnesium in Ayurvedic therapy and lays a correlation with $\mathrm{Mg}$ levels in Synovial fluid and Bursal fluid.

\section{Conclusions}

A detailed understanding of inflammation induced modification of $\mathrm{Mg}$ levels in Synovial/Bursal Fluid of knee joint may help to draw some important points. The Arthritis patients with severe $\mathrm{Mg}$ deficiency led us to hypothesize that long lasting $\mathrm{Mg}$ depletion in Synovial fluid could have been one of the cause of underlying disease. Thus, the diminished $\mathrm{Mg}$ status can serve as a potential diagnostic marker in assessment of joint disorders. Further, ICP-AES technique of measurement of element in synovial/Bursal fluid has proved its niche as an important tool in monitoring chemical dynamics in transcellular fluid. The data provided may also be useful in nutritional studies and in the study of joint physiology and pathology.

The results are quite promising for the application of polyherbal formulation as an antiarthritis ayurvedic medicinal agent due to its inhibitory action on some of the mediators of inflammation. This prospective study of patients suffering from arthritis and healthy adult volunteers, caters the essentiality of mineral; $\mathrm{Mg}$ in etiology of arthritis. In addition to that, it has provided scientific evidences of potential role of $\mathrm{Mg}$ in polyherbal formulation and its correlation in joint fluids. Moreover, further clinical trials may support its stronger therapeutic use. Secondly, it may provide new rationale for use of $\mathrm{Mg}$ preparations in the therapy of inflammatory and non inflammatory joint disorders.

\section{References}

1. Angus $\mathrm{M}$ and Sambrook N. Dietary intake and bone mineral density. Bone Miner. 1988; 4; 265-270.

2. Tucker L, Hannan T, Chen H, Cupples A, Wilson F and Kiel D. Potassium, magnesium, and fruit and vegetable intakes are associated with greater bone mineral density in elderly men and women. Is J Clin Nutr. 1999; 69; 727-736.

3. Rude K, Gruber E, Wei Y, Frausto A and Mills G. Effect on bone and mineral metabolism in the mouse .Calcif Tissue Int. 2003; 72; 32-41.

4. Stendig L, Tepper R and Leichter I. Trabecular bone density in a two year controlled trial of peroral magnesium in osteoporosis. Magnes Res. 1993; 6; 155-63.

5. Cohen L, Laor A and Kitzes R. Magnesium malabsorption in postmenopausal osteoporosis. Magnesium.1983; 2; 139-43. 
6. Sojka E and Weaver M. Magnesium supplementation and osteoporosis. Nutr Rev.1995; 53; 71-80.

7. Scotchford C.A and Ali S.Y. Magnesium whitlockite deposition in articular cartilage: a study of 80 specimens from 70 patients. Ann Rheum Dis. 1995; 54; 339-344.

8. Schroeder H.A, Nason A.P and Tipton I.H. Essential Metals in Man. Magnesium. J. Chron. Dis.1969; 21; 815-841.

9. Cohen L and Kitzes R. Pseudogout with low values of magnesium and low alkaline phosphatase activity in synovial fluid. Isr J Med Sci. 1983; 19(9); 838-40.

10. WMA Declaration of Helsinki Ethical Principles for Medical Research Involving Human Subjects $18^{\text {th }}$ WMA General Assembly, Helsinki. 1964.

11. Tuncer S, Kamanli A, Akçil E, Kavas G.O, Seçkin B and Atay M.B. Trace element and magnesium levels and superoxide dismutase activity in rheumatoid arthritis. Biol Trace Elem Res. 1999; 68(2); 137-42.

12. www.pathlights.com/nr_encyclopedia/ onlinebooks/Arthriitis/arthritis2.html

13. Dominguez L.J. et al. Magnesium and muscle performance in older persons: the InCHIANTI study. The American Journal of Clinical Nutrition. 2006; 84; 419-26.

14. Rude K, Singer R and Gruber E. Skeletal and hormonal effects of magnesium Deficiency. Jam coll Nutr.2009; 28(2); 131-41.

15. Sowers $M$ et al. The associations of bone mineral density and bone turnover markers with osteoarthritis of the hand and knee in pre- and perimenopausal women. Arthritis. Rheum.1999; 42; 483-9.

16. Afridi H.I, Kazi T.G, Kazi N, Shah A.Q, Khan S, Kolachi N.F, Wadhwa S.K, and Shah F. Evaluation of calcium, magnesium, potassium, and sodium in biological samples (scalp hair, serum, blood, and urine) of Pakistani referents and arthritis patients of different age groups. Clin Lab. 2012; 58(1-2); 7-18.

17. Feghali $\mathrm{C}$ and Wright T. Cytokines in Acute and Chronic Inflammation. Frontiers in Bioscience. 1997; 2; 21-26.

18. Clegg P.D, Coughlan A.R, Riggs C.M, Carter S.D. Matrix metalloproteinases 2 and 9 in equine synovial fluids. Equine Vet J.1997; 29; 343-348.

19. Srivastava K.C, Mustafa T. Ginger (Zingiber officinale) in rheumatism and musculoskeletal disorders. Med Hypoth.1992; 39; 342-48.

20. Deodhar S.D, Sethi R, Srimal R.C. Preliminary study on antirheumatic activity of curcumin. Indian $\mathrm{J}$ Med Res.1980; 71; 632-34.

21. Kahkonen M.P et al. Antioxidant activity of plant extracts containing phenolic compounds. Journal of Agricultural and Food Chemistry. 1999; 47; 3954-3962.

22. Arora R, Basu N, Kapoor V. Antiinflammatory studies on Curcuma longa (turmeric), Indian Journal of Medical Reserch.1971; 59; 1289-95.

23. Siddalingappa C.M, Rajesh T, Kudagi B.L, Krishnakanth K, Sujith T.R. Evaluation of analgesic and antiinflammatory activities of Tinospora cordifolia in rodents. International Journal of Basic medical science. 2012.

24. .Anbalagan K, Sadique J. Influence of an Indian medicine (Ashwagandha) on acutephase reactants in inflammation. Indian J Exp Biol.1981; 19; 245-249.

25. Baburao B, Rajyalakshmi G, Venkatesham A, Kiran G, Sunder A and Rao B.G. Anti-inflammatory and antimicrobial activities of methanolic extract of Tribulus terrestris Linn plant. International Journal of Chemical Sciences. 2009; 7 (3); 1867 1872. 
26. Thomson M, Al-Qattan K.K, AlSawan S.M, Alnaqeeb M.A, Khan I, Ali M. The use of ginger (Zingiber officinale Rosc.) as a potential antiinflammatory and antithrombotic agent. Prostaglandins Leukotrienes and Essential Fatty Acids. 2002; 67 (6); 475-478.

27. Sharrard W.J.W. Aetiology and pathology of beat knee. Brit. J. industr. Med. 1963; 20; 24.

28. Sumantran V.N, Kulkarni A.A, Harsulkar A, Wele A, Koppikar S.J, Chandwaskar R, Gaire V, Dalvi M and Wagh U.V. Hyaluronidase and collagenase inhibitory activities of the herbal formulation Triphala guggulu. J. Biosci. 2007; 32; 755-76.

29. Abraham S. Evaluation of the Inhibitory Effect of Triphala on PMNType Matrix Metalloproteinase (MMP9). Journal of Periodontology. 2005; 76(4); 497-502.

30. Guo H, Lee J.D, Uzui H, Yue H, Wang J, Toyoda K, Geshi T, Ueda T. Effects of folic acid and magnesium on the production of homocysteine-induced extracellular matrix metalloproteinase2 in cultured rat vascular smooth muscle cells. Journal of the Japanese Circulation Society. 2007; 70(1); 1416. 